\title{
UTILIZAÇÃO DE NITRATO DE AMÔNIO E DE URÉIA COMO FONTES DE NITROGÊNIO NA MICROPROPAGAÇÃO DE AMOREIRA-PRETA
}

\section{UTILIZATION OF AMONIUM NITRATE AND UREA AS NITROGEN SOURCES IN THE BLACKBERRY MICROPROPAGATION}

\author{
Fabíola VILLA ${ }^{1}$ \\ Moacir PASQUAL ${ }^{2}$ \\ Leila Aparecida Salles $\mathrm{PIO}^{3}$ \\ Chrystiane Borges FRÁGUAS ${ }^{4}$ \\ Juliana Costa de REZENDE ${ }^{5}$
}

\section{RESUMO}

O elevado custo do nitrato de amônio, aliado à dificuldade de aquisição do mesmo, tem levado à realização de trabalhos, no sentido de buscar alternativas para a substituição dessa fonte de nitrogênio. Objetivou-se estudar a viabilidade técnica da substituição do nitrato de amônio por uréia, como fonte de nitrogênio no meio de cultura para o cultivo in vitro de amoreira-preta (Rubus sp) cultivar Tupy. Segmentos nodais de brotações pré-estabelecidas in vitro, foram inoculados em meio de cultura MS (Murashige \& Skoog) e $50 \% \mathrm{MS}$, acrescido de $1,0 \mathrm{mg} \mathrm{dm}^{-3}$ de BAP, solidificado com $6 \mathrm{~g} \mathrm{dm}^{-3} \mathrm{de}$ ágar, $\mathrm{pH}$ ajustado para 5,8 e esterilizado a $121^{\circ} \mathrm{C}$ e $0,1 \mathrm{MPa}$ por $20 \mathrm{~min}$. Os tratamentos consistiram da substituição de $0 ; 20 ; 40 ; 60$; 80 e $100 \%$ do $\mathrm{NH}_{4} \mathrm{NO}_{3}$ por uréia, não sendo alterado o balanço de nitrogênio fornecido pelo meio $\mathrm{MS}$. Os explantes foram mantidos por 60 dias em sala de crescimento com temperatura de $27 \pm 1^{\circ} \mathrm{C}$, irradiância de $32 \mu \mathrm{mol} \mathrm{m} \mathrm{m}^{-2} \mathrm{~s}^{-1}$ e fotoperíodo de 16 h. O delineamento experimental utilizado foi inteiramente casualisado, em esquema fatorial $(6 \times 2)$, utilizando-se de quatro repetições constituídas de quatro tubos contendo um explante cada. Com base nos resultados obtidos, pode-se concluir que é possível a substituição parcial do nitrato de amônio no meio MS na micropropagação da amoreira-preta cv. Tupy.

Palavras-chave: nitrogênio; meio de cultura MS; Rubus sp.

\section{ABSTRACT}

The high cost allied to the difficulty in the acquisition of the ammonium nitrate has been taking the accomplishment of works looking for an alternative for the substitution of this source of nitrogen. It was aimed at to study the technical viability of the substitution of the ammonium nitrate for urea, as source of nitrogen in the culture media for the blackberry in vitro cv. Tupy (Rubus sp). Nodal segments were used, already established in vitro, were inoculated in culture media MS and $50 \% \mathrm{MS}$, added of $1.0 \mathrm{mg} \cdot \mathrm{dm}^{-3}$ of BAP, solidified with $6 \mathrm{~g}_{\mathrm{dm}} \mathrm{dm}^{-3}$ of agar, $\mathrm{pH}$ was adjusted for 5,8 and sterilized to $121^{\circ} \mathrm{C}$ and $0,1 \mathrm{MPa}$ for 20 min. The treatments consisted of the substitution of $0 ; 20 ; 40 ; 60 ; 80$ and $100 \%$ of $\mathrm{NH}_{4} \mathrm{NO}_{3}$ for urea, and the swinging of nitrogen supplied by the culture media MS it was not altered. The explants were maintained by 60 days in growth room with temperature of $27 \pm 1{ }^{\circ} \mathrm{C}$, photoperiod of $16 \mathrm{~h}$ and luminous intensity of $32 \mathrm{mmol} \mathrm{m}^{-2} \mathrm{~s}^{-1}$. The experiment was arranged in a completely randomized design, in factorial $(6 \times 2)$ using four repetitions with 16 plants each one. From the obtained results it can be concluded that the urea doesn't substitute $\mathrm{NH}_{4} \mathrm{NO}_{3}$ in the culture media MS as nitrogen source in the culture vitro of blackberry.

Key-words: nitrogen; culture media MS; Rubus sp.

\footnotetext{
${ }^{1}$ Pós-doutoranda em Fitotecnia, Empresa de Pesquisa Agropecuária de Minas (EPAMIG) / Fundação de Amparo à Pesquisa de Minas Gerais (FAPEMIG), Av. Washington Viglione, s/n Maria da Fé, Minas Gerais, CEP: 37517-000. E-mail: fvilla2003@libero.it. Autor para correspondência ${ }^{2}$ D.Sc., Professor Adjunto, Departamento de Agricultura (DAG), Universidade Federal de Lavras (UFLA), Lavras, Minas Gerais, Brasil. CEP 37200-000. E-mail: mpasqual@ufla.br

${ }^{3}$ Pós-doutoranda em Citogenética, Departamento de Biologia, Universidade Federal de Lavras (UFLA), Lavras, Minas Gerais, Brasil. E-mail: leilapio@ufla.br

${ }^{4}$ Doutora em Produção Vegetal, Faculdade de Ciências Agrárias e Veterinárias (FCAV), Universidade Estadual Paulista "Júlio de Mesquita Filho" (UNESP), Botucatu, São Paulo, Brasil. E-mail: chrysbf@uol.com.br

${ }^{5}$ D.Sc., Pesquisadora da Empresa de Pesquisa Agropecuária de Minas Gerais (EPAMIG), Lavras, Minas Gerais, Brasil. E-mail: julianacosta@epamig.br
} 
VILLA, F. et al. Utilização de nitrato de amônio e de uréia como fontes...

\section{INTRODUÇÃO}

Os maiores produtores de amora-preta na América do Sul são a Argentina e o Chile. O Brasil, apesar de seu grande potencial, não apresenta produção significativa desta fruta. $O$ estado que se destaca é o Rio Grande do Sul, onde se encontra a Embrapa Clima Temperado, que desenvolve pesquisas com pequenos frutos. Além deste estado, a amoreira-preta é também cultivada por pequenos produtores de Santa Catarina, Paraná e Sul de Minas Gerais (Augusto et al., 2006; Antunes, 2002). $O$ meio de cultura utilizado na micropropagação é um fator determinante para o sucesso do cultivo in vitro de frutíferas. A fonte de sais minerais fornecida aos explantes é extremamente importante, assim como sua concentração. O nitrogênio é um dos principais nutrientes essenciais e ativos, sendo absorvido, principalmente, na forma de nitrato $\left(\mathrm{NO}_{3}{ }^{-}\right)$e amônio $\left(\mathrm{NH}_{4}{ }^{+}\right)$. Por ser constituinte de várias biomoléculas essenciais, como aminoácidos,ácidos nucléicos, proteínas, enzimas e outros, sua assimilação se dá em diversos processos metabólicos da planta (Sakuta et al., 1987). Sabe-se que as fontes de nitrogênio são de grande importância tanto no crescimento quanto na diferenciação de células e tecidos cultivados in vitro (Van Beusichem et al., 1988).

Dados de vários autores (Grattapaglia \& Machado, 2004; Araujo et al., 2009), mostram que é a combinação de amônio e nitrato que estimula o crescimento de várias espécies de plantas in vitro. A razão entre estas duas fontes de nitrogênio, para os autores em consideração, parece ser o fator determinante causador deste estímulo.

Entretanto, o efeito benéfico de ambas as formas de nitrogênio $\left(\mathrm{NO}_{3}{ }^{-} \mathrm{e} \mathrm{NH}_{4}{ }^{+}\right)$ainda não é bem entendido (Lu et al., 2009; Niedz \& Evens, 2008). Além das formas inorgânicas de nitrogênio, podem ser fornecidas as formas orgânicas, as quais são prontamente assimiláveis pelas células vegetais. As formas específicas de nitrogênio orgânico incluem uréia, aminoácidos, poliaminas e ureídeos (Grothge, 1992). Embora as frutíferas de clima temperado sejam objeto de pesquisa, existem poucos trabalhos realizados com essas espécies na tentativa de se estudar fontes alternativas de nitrogênio no cultivo in vitro.

Polacco (1977) verificou o crescimento de células de soja em suspensão quando forneceu uréia ao meio, juntamente com a adição de níquel. Incrementos no número de brotações também foram obtidos para algumas espécies ao serem cultivadas em meio de cultura com adição de uréia (bromélia - Endres \& Mercier, 2001). Entretanto, culturas que foram estabelecidas em meio contendo uréia como única fonte de nitrogênio cresceram mais lentamente que células mantidas em meio de cultura contendo nitrato e amônio.

Por outro lado, o elevado custo do nitrato de amônio, em relação à uréia, aliado à dificuldade de aquisição do mesmo, tem levado à realização de trabalhos, no sentido de buscar alternativas para a substituição dessa fonte de nitrogênio. Pode afirmar que, $1 \mathrm{~kg}$ de nitrato de amônio custa $\mathrm{R} \$ 2.296,00 \mathrm{e}$ $1000 \mathrm{~kg}$ de uréia pode-se adquirir pelo preço de $\mathrm{R} \$$ 856,00 .

Nesse contexto, objetivou-se estudar a viabilidade técnica da substituição do nitrato de amônio por uréia, como fonte de nitrogênio; em diferentes concentrações de meio de cultura, para o cultivo in vitro de amoreira-preta cultivar Tupy.

\section{MATERIAL E MÉTODOS}

O experimento foi realizado no Laboratório de Cultura de Tecidos Vegetais, localizado no Departamento de Agricultura, da Universidade Federal de Lavras (UFLA), Lavras, MG.

Segmentos nodais de brotações préestabelecidas in vitro, foram inoculados em meio de cultura MS (Murashige \& Skoog, 1962) e $1 / 2$ MS, acrescido de $1,0 \mathrm{mg} \mathrm{dm}^{-3}$ de BAP (6benzilaminopurina), solidificado com $6 \mathrm{~g} \mathrm{dm}^{-3}$ de ágar, pH ajustado para 5,8 e autoclavado a $121{ }^{\circ} \mathrm{C}$ e $0,1 \mathrm{MPa}$ por $20 \mathrm{~min}$. Os tratamentos consistiram da substituição de $0 ; 20 ; 40 ; 60 ; 80$ e $100 \%$ do nitrato de amônio $\left(\mathrm{NH}_{4} \mathrm{NO}_{3}\right)$ por uréia $\left(\mathrm{CH}_{4} \mathrm{~N}_{2} \mathrm{O}\right)$, não sendo alterado $\mathrm{O}$ balanço de nitrogênio fornecido pelo meio MS. Os segmentos nodais de amoreira-preta cultivar Tupy (2 subcultivos) foram inoculados em tubos de ensaio $(20 \times 150 \mathrm{~mm})$, contendo $12 \mathrm{~cm}^{3}$ do meio de cultura e posteriormente mantidos em sala de crescimento, onde foram mantidos por 60 dias em sala de crescimento com temperatura de $27 \pm 1{ }^{\circ} \mathrm{C}$, irradiância de $32 \mu \mathrm{mol} \mathrm{m} \mathrm{m}^{-2} \mathrm{~s}^{-1}$ e fotoperíodo de $16 \mathrm{~h}$. $\mathrm{O}$ delineamento experimental utilizado foi inteiramente casualisado, utilizando-se de quatro repetições constituídas de quatro tubos contendo um explante cada. As variáveis analisadas foram número de folhas, massa fresca e comprimento da parte aérea e número de raízes. Os resultados foram submetidos à análise de variância, utilizandose do software Sisvar (Ferreira, 2000) e obtendo-se regressões para as concentrações de uréia.

\section{RESULTADOS E DISCUSSÃO}

Observa-se com base na análise de variância que o efeito da uréia em meio de cultura MS e $1 / 2$ MS foi significativo apenas para massa fresca da parte aérea e número de raízes. De forma quadrática, todas as variáveis analisadas tiveram um decréscimo com o incremento de concentrações de uréia, evidenciando que os explantes de amoreira-preta 'Tupy', por serem constituídos de tecidos mais tenros, são mais sensíveis ao efeito da uréia, provavelmente devido à um efeito fitotóxico.

Não se verificou interação significativa do nitrato de amônio e da uréia para número de folhas (Figura 1). Apenas as concentrações de uréia foram significativas, onde maior número de folhas de amoreira-preta foi observado na ausência do referido sal. 
VILLA, F. et al. Utilização de nitrato de amônio e de uréia como fontes...

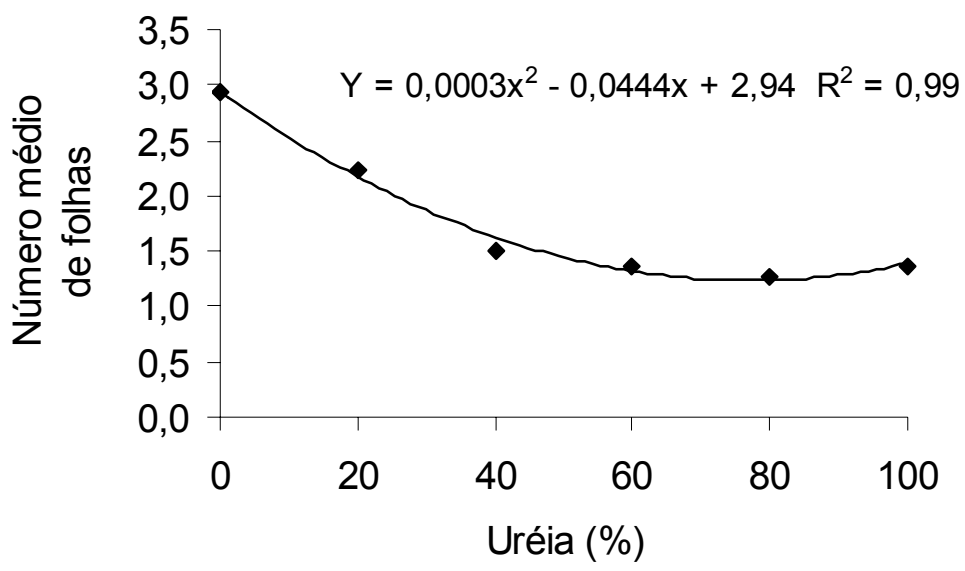

FIGURA 1 - Número de folhas de amoreira-preta 'Tupy' (Rubus sp.), cultivada em diferentes concentrações de uréia $\left(\mathrm{CH}_{4} \mathrm{~N}_{2} \mathrm{O}\right)$, UFLA, Lavras, MG.

Geralmente, a utilização de uréia em concentrações ideais proporciona aumento no teor de clorofila, intensificando a coloração dos explantes e apresentando aspecto vigoroso (Grothge, 1992). Marques et al. (1998), estudando a influência de fontes de nitrogênio sobre 0 desenvolvimento de gemas axilares de explantes caulinares de crisântemo, verificaram uma coloração verde intenso nas folhas dos tratamentos onde uréia foi adicionada ao meio de cultura MS. Entretanto, no presente trabalho, observou-se diminuição na coloração típica das folhas de amoreira-preta quando cultivadas em meio contendo no mínimo $20 \%$ de uréia, mostrando o início do efeito de fitotoxidade proveniente da uréia. Melhor resultado para as variáveis estudadas foi obtido na ausência de uréia, isto é, na concentração padrão de $\mathrm{NH}_{4} \mathrm{NO}_{3}$ do meio de cultura MS.
Maior ou menor efeito de fitotoxidade da uréia depende da concentração adicionada ao meio e do explante utilizado. Plantas lenhosas, geralmente, são mais resistentes e aproveitam melhor o nitrogênio prontamente disponibilizado na forma de uréia. Diferentemente, a amoreira-preta, e que possui tecidos mais tenros, é mais sensível, principalmente quando cultivada in vitro. Devido à essa susceptibilidade, maiores concentrações de uréia adicionadas ao meio de cultivo, levam a um efeito fitotóxico nos explantes de amoreira-preta.

O conteúdo de massa fresca comportouse semelhantemente às demais variáveis, em que os explantes cultivados na ausência de uréia e em $1 / 2$ MS apresentaram os melhores resultados (Figura 2), corroborando Moreira et al. (2007), que obtiveram melhores resultados de matéria fresca na micropropagação de mudas abacaxizeiro quando cultivados em meio MS na ausência do referido sal.

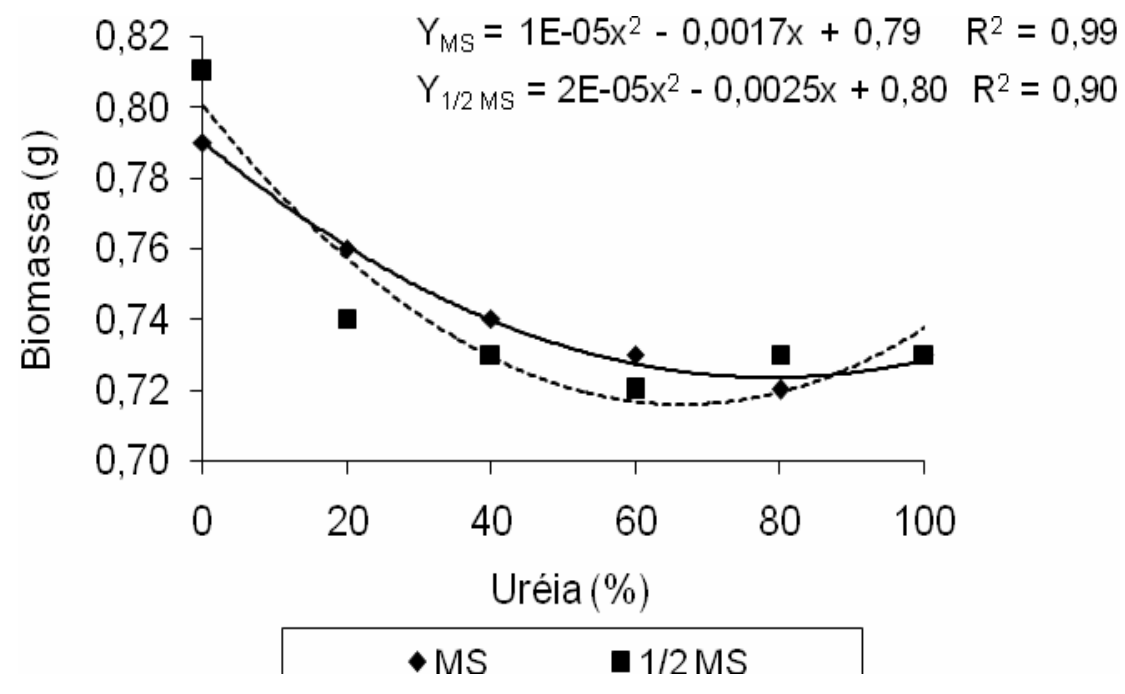

FIGURA 2 - Biomassa de amoreira-preta 'Tupy' (Rubus sp.), cultivada em diferentes concentrações de meio de cultura MS e de uréia $\left(\mathrm{CH}_{4} \mathrm{~N}_{2} \mathrm{O}\right)$, UFLA, Lavras, MG. 
VILLA, F. et al. Utilização de nitrato de amônio e de uréia como fontes...

Houve interação significativa para a variável massa fresca de amoreira-preta, onde maior massa $(0,81 \mathrm{~g})$ foi observado em $1 / 2 \mathrm{MS}$, na ausência de uréia, ou seja, na concentração original de nitrato de amônio do meio de cultura.

Grothge (1992), trabalhando com o clone G0694 de eucalipto, obteve maior massa da matéria fresca $(0,51 \mathrm{~g})$ utilizando $100 \mathrm{mg} \mathrm{dm}^{-3} \mathrm{de}$ uréia. No entanto, quando utilizou concentrações maiores (200 e $300 \mathrm{mg} \mathrm{dm}^{-3}$ ), verificou decréscimo na matéria fresca $(0,23$ e $0,21 \mathrm{~g}$, respectivamente), evidenciando que altas concentrações de uréia no meio de cultura podem tornar-se fitotóxicas.

Maior comprimento da parte aérea $(4,34$ $\mathrm{cm}$ ) foi obtido em explantes cultivados na ausência de uréia (Figura 3). Na concentração de $20 \%$ de uréia adicionada ao meio de cultura, registrou-se um comprimento da ordem de $3,29 \mathrm{~cm}$. Esse menor comprimento da parte aérea ocorreu provavelmente devido ao efeito fitotóxico provocado pela uréia nos explantes. Resultados contrários foram obtidos por Grothge (1992), quando observou efeito benéfico da adição de uréia no meio de cultura para o crescimento e desenvolvimento de explantes de Eucaliptus grandis Hill. ex Maiden. Quando a uréia foi empregada como única fonte de nitrogênio em meio de cultura MS, houve tanto promoção da parte aérea como no número e comprimento das raízes de Chrysanthemum morifolium Ramat. Porém, esse desenvolvimento foi inferior àqueles obtidos nos tratamentos onde uréia e nitrato estiveram presentes (Marques et al., 1998). Espécies diferentes podem ter respostas diversas às concentrações de outros componentes à base de nitrogênio (N) (Lu et al., 2009; Araujo et al., 2009).

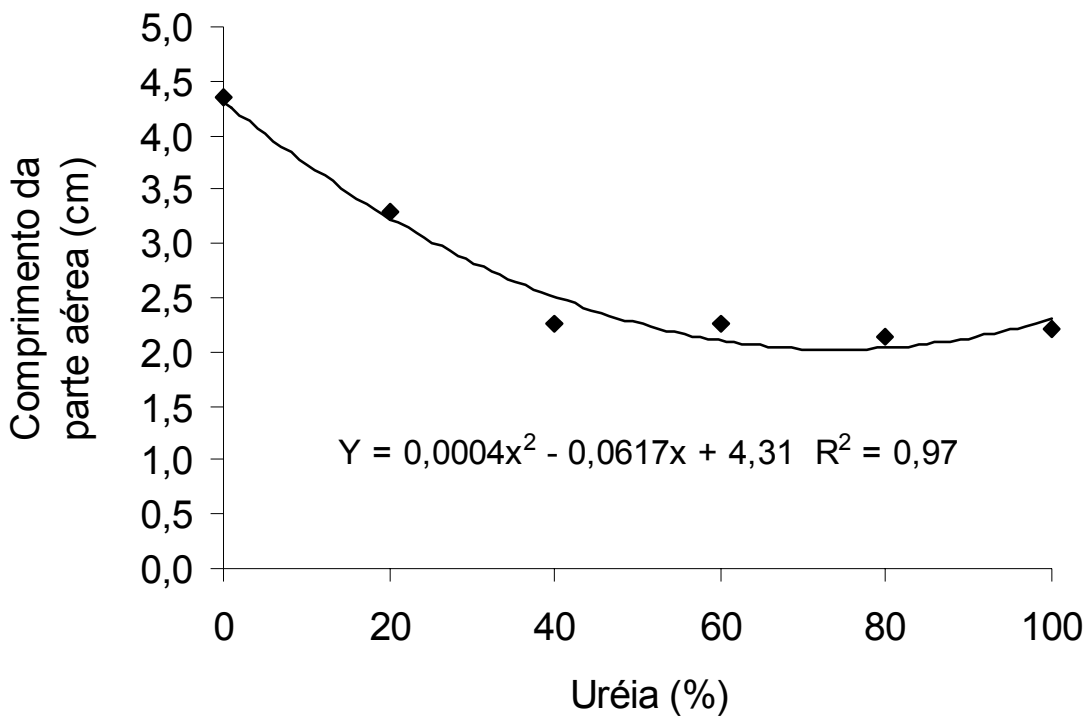

FIGURA 3 - Comprimento da parte aérea (cm) de amoreira-preta 'Tupy' (Rubus sp.), cultivada em diferentes concentrações de uréia $\left(\mathrm{CH}_{4} \mathrm{~N}_{2} \mathrm{O}\right)$, UFLA, Lavras, MG.

Porém, em trabalho com micropropagação de abacaxizeiro cv. Pérola, Moreira et al. (2007) constataram que, os brotos se desenvolveram quando cultivados em meio de cultura MS, na ausência de uréia. Melhores brotações de caffeeiro (Coffea arabica L.) foram verificadas quando se reduziu a concentração do nitrato de amônio $\left(\mathrm{NH}_{4} \mathrm{NO}_{3}\right)$ em $50 \%$ (Ribeiro et al., 2002).

Não foi verificada interação significativa para número de raízes e, na ausência de uréia, ou seja, na concentração original do meio MS, foi verificado um maior número de raízes $(1,77)$ das plantas (Figura 4). Com o aumento nas concentrações de uréia, houve um decréscimo no número de raízes de forma quadrática até $80 \%$ deste sal.

Com base nos resultados obtidos, tornamse necessários novos estudos que avaliem concentrações inferiores a $20 \mathrm{mg} \mathrm{dm}^{-3}$ de uréia no meio combinadas com diferentes concentrações de meio de cultura MS às utilizadas, a fim de eliminar o provável efeito inibitório da multiplicação causado pela uréia. Fráguas et al. (2003) concluíram que concentrações superiores a $20 \mathrm{mg} \mathrm{dm}^{-3}$ de uréia são tóxicas ao cultivo in vitro de gloxínia devido, possivelmente, a um efeito inibitório de BAP (6-benzilaminopurina) pela uréia, adicionada ao meio de cultura. 
VILLA, F. et al. Utilização de nitrato de amônio e de uréia como fontes...

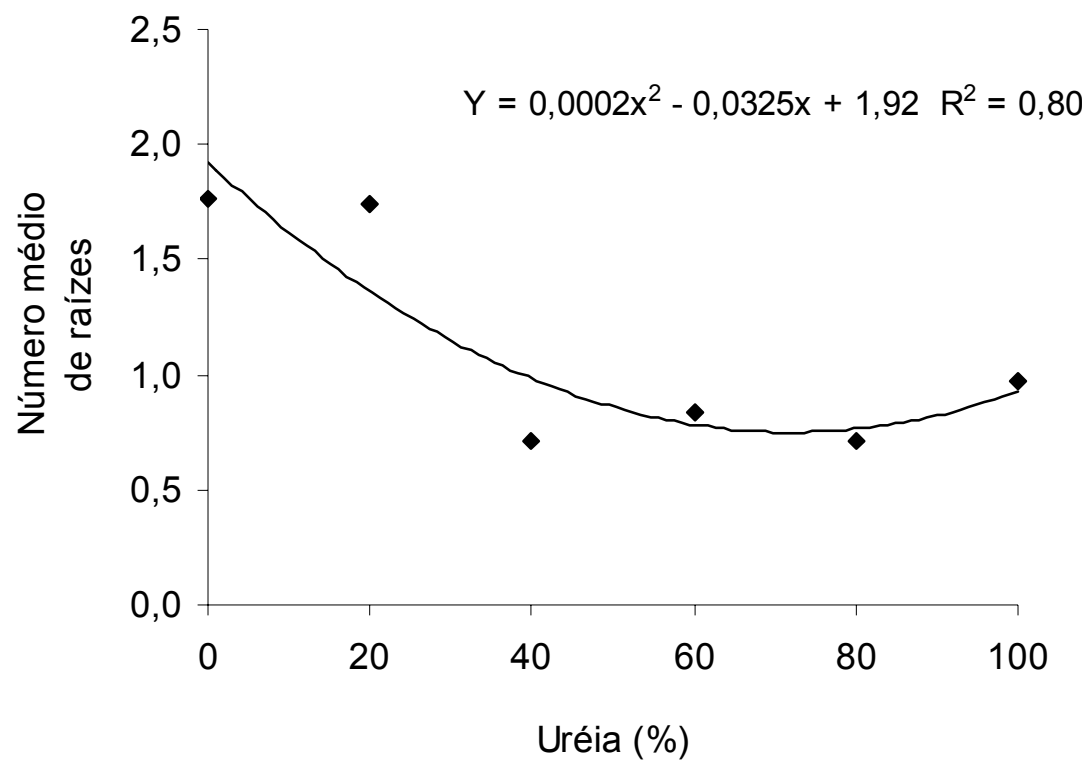

FIGURA 4 - Número de raízes de amoreira-preta 'Tupy' (Rubus sp.), cultivada em diferentes concentrações de uréia $\left(\mathrm{CH}_{4} \mathrm{~N}_{2} \mathrm{O}\right)$, UFLA, Lavras, MG.

À medida que se aumenta a concentração de uréia no meio de cultura sólido, diminuem a altura das plantas, o número de folhas e massa fresca da parte aérea, possivelmente ao efeito fitotóxico da uréia quando utilizada em maiores quantidades. Porém é possível a substituição parcial sem prejudicar o desenvolvimento da planta se comparada à ausência da uréia. Essa substituição pode ser suficiente para a redução de custos para o cultivo in vitro de pequenas frutas.

\section{CONCLUSÕES}

É possível a substituição parcial do nitrato de amônio no meio MS na micropropagação da amoreira-preta cv. Tupy.

Concentrações superiores a $20 \mathrm{mg} \mathrm{dm}^{-3}$ de uréia são tóxicas ao cultivo in vitro de amoreirapreta cv. Tupy.

\section{REFERÊNCIAS}

1. ANTUNES, L. E. C. Amora-preta: nova opção de cultivo no Brasil. Ciência Rural, v. 32, n. 1, p. 151-158, 2002.

2. ARAUJO, A. G. et al. Fontes de nitrogênio no crescimento in vitro de plântulas de Cattleya loddigesii Lindl. (Orchidaceae). Acta Scientiarum. Biological Sciences, v. 31, n. 1, p. 35-39, 2009.

3. AUGUSTO, C. S. S.; BIASI, L. A.; TELLES, C. A. Enraizamento e aclimatização de plantas micropropagadas de amoreirapreta cv. Brazos. Revista Brasileira de Fruticultura, v. 28, n. 3, p. 473-476, 2006.

4. ENDRES, L.; MERCIER, H. Ammonium and urea as nitrogen sources for bromeliads. Journal of Plant Physiology, v. 158, n. 2, p. 205-212, 2001.

5. FERREIRA, D. F. Análises estatísticas por meio do Sisvar para Windows versão 4.0. In: REUNIÃO ANUAL DA REGIÃO BRASILEIRA DA SOCIEDADE INTERNACIONAL DE BIOMETRIA, 45, 2000, São Carlos. Anais... São Carlos: UFSCar, 2000. p. 255-258

6. FRÁGUAS, C. B. et al. Micropropagação de gloxínia em diferentes concentrações de nitrato de amônio e uréia. Ciência e Agrotecnologia, v. 27, n. 4, p. 811-815, 2003.

7. GRATTAPAGLIA, D.; MACHADO, M. A. Micropropagação. In: TORRES, A. C.; CALDAS, L. S. (Ed.). Técnicas e aplicação da cultura de tecidos de plantas. Brasília: EMBRAPA/CNPH, 2004, p. 99-169.

8. GROTHGE, M. T. Efeito de várias fontes de nitrogênio na multiplicação in vitro de clones de Eucalyptus grandis HILL ex MAIDEN. 1992. 86 p. Dissertação (Mestrado em fisiologia bioquímica de plantas) - Escola Superior de Agricultura Luiz de Queiroz, Universidade de São Paulo, Piracicaba, 1992.

9. LU, Y. L. et al. Effects of different nitrogen forms on the growth and cytokinin content in xylem sap of tomato (Lycopersicon esculentum Mill.) seedlings. Plant and Soil, v. 315, n. 12, n. 1-2, p. 67-77, 2009.

10.MARQUES, D. A.; SHEPHERD, S. L. K.; CROCOMO, O. J. Influência de fontes de nitrogênio sobre o desenvolvimento das gemas axilares de explantes caulinares de Chrysanthemum morifolium Ramat. cultivado in vitro. Revista Brasileira de Botânica, v. 21, n. 2, p. 141-147, 1998.

11.MOREIRA, M. A. et al. Uréia como fonte alternativa de nitrogênio na micropropagação de abacaxizeiro cv. Pérola. Acta Scientiarum Agronomy, v. 29, n. 5 (supl. especial), p. 689-693, 2007.

12.MURASHIGE, T.; SKOOG, F. A. A revised medium for rapid growth and bioassays with tobacco tissue cultures. Physiologia Plantarum, v. 15, n. 3, p. 473-497, 1962. 
VILLA, F. et al. Utilização de nitrato de amônio e de uréia como fontes...

13. NIEDZ, R. P.; EVENS, T. J. The effects of nitrogen and potassium nutrition on the growth of nonembryogenic and embryogenic tissue of sweet orange (Citrus sinensis (L.) Osbeck). BMC Plant Biology, v. 8, p. 1-11, 2008.

14. POLACCO, J. C. Nitrogen metabolism in soybean tissue culture II: urea utilization and urease synthesis require $\mathrm{Ni}^{+2}$. Plant Physiology, v. 59, n. 5, p. 827-830, 1977.

15. RIBEIRO, L. S. et al. Fontes de nitrogênio na micropropagação de Coffea arabica. Scientia Agraria, v. 3, n. 1-2, p. 107$112,2002$.

16. SAKUTA, M. et al. Effects of sucrose source on betacyanin accumulation and growth in suspension cultures of Phytolacea americana. Physiologia Plantarum, v. 71, n. 4, p. 459-463, 1987.

17. VAN BEUSICHEM, M. L.; KIRKBY, E. A.; BAAS, R. Influence of nitrate and ammonium nutrition and the uptake, assimilation and distribution of nutrient in Ricinus communis. Plant Physiology, v. 86, n. 3, p. 914-921, 1988.

Recebido em 12/03/2009

Aceito em 22/06/2009 